\title{
Overheads as a Performance Indicator in the Local Public Sector Organizations
}

\author{
Christian Rainero ${ }^{1}$, Alessandro Migliavacca ${ }^{2} \&$ Sara Reano $^{3}$ \\ ${ }^{1}$ Associate professor, Department of Management, University of Turin, Italy \\ ${ }^{2}$ Researcher, Assistant professor, Department of Economics, Management and Quantitative Methods, University \\ of Milan Statale, Italy \\ ${ }^{3}$ Ph.D. Student, Department of Management, University of Turin, Italy \\ Correspondence: Alessandro Migliavacca, Department of Economics, Management and Quantitative Methods, \\ University of Milan Statale, Italy. E-mail: alessandro.migliavacca@unimi.it
}

Received: May 14, 2020

Accepted: June 20, 2020

Online Published: June 29, 2020

doi:10.5539/ijbm.v15n8p1

URL: https://doi.org/10.5539/ijbm.v15n8p1

\begin{abstract}
If we consider business forms from the point of view of satisfying needs, public companies are consumer companies that satisfy collective needs with the aim of redistributing income. They differ from production companies in that they do not have direct access to the market, so that the sources of financing derive from the taxes imposed by law, while the uses concern management costs, capital investments and debt repayments. Maintaining this interpretation, another category belonging to consumer companies is that of non-profit companies, which can be equated partially to public companies precisely because of the absence of a real market of reference and the finding of sources of funding for the performance of the activity mainly from external contributions without consideration. The only difference is inherent in the fact that such contributions cannot be imposed by law and are aimed at assisting and providing services and benefits to the community of reference, in the absence of profit and capital distribution. Therefore, if in the public sector performance is mainly and historically linked to the management of financial resources and public debt, in the field of nonprofit there is a different literature focused more on the control of economic aspects (and in particular the costs of the activity) as performance indicators of the company's activity. At the international level, and in particular in the United States, the use of the incidence of overheads is an element of examination to assess the performance of the non-profit sector. In this article, the subject of analysis is the possibility of using the overhead level to assess the performance of a public body. The analysis is carried out by comparing the incidence of overheads on the revenues of Italian municipalities in the years 2015-2017 with the performance indicators given by the deficit parameters established by current administrative legislation. From this analysis, it is possible to identify the presence of a correlation between the performance indicators and the incidence of overheads, in which the likelihood of the presence of "good", "excellent" or "excellent" indicators is given by levels of overhead in the region of $10 \%$ of the total revenue assessed, with a margin of tolerance of $3 \%$ in positive for smaller entities (up to 5,000 inhabitants), and $3 \%$ in negative for larger entities.
\end{abstract}

Keywords: overhead, local public sector, performance indicators

\section{Introduction}

In the last two decades, the New Public Management wave has driven a shift in public sector accounting techniques to build the foundations of sustainable and inclusive societies (OECD 2015, 11). This renewal had tried to go in the same direction in all countries, and particularly in Europe, but with times and methods linked to the traditions of individual countries that have not always led to uniform results (Brusca et al., 2016).

Many factors have affected and accelerated this mechanism. These include the request by stakeholders for transparency in the applied principles and purposes of public sector accounting, the economic crisis, and the development of IPSAS (International Public Sector Accounting Standards).

In Italy, this process of harmonization of public sector accounting began in 2011 with applications starting in 2013, becoming effective in 2018. This process aimed to make general government financial statements homogeneous, comparable, and available for aggregation and citizens' consideration. This is not only an 
accounting reform (now mandatory for all), but a reform that must be integrated and spread within the organizational context of the organization, both through the diffusion of new management culture and through the adaptation of computerized management tools, but also through a new budget structure that must be integrated with the organizational structure of the organization itself (Anessi Pessina, 2018).

Accounting is the mechanism by which the economy of organized life is elaborated and institutionalized; at a theoretical level the main roles of accounting are (Miller e Power 2013):

- Territorializing (creation of an informed context that fulfills the training of awareness of the results of the management and the work of the organization);

- Mediating (a role of external communication of the activities of the organization and of its results);

- Adjudicating (the possibility of submitting activities to stakeholders for their opinion);

- Subjectivizing (making the organization's activities subject to control by the competent bodies).

In light of this interpretative framework, this contribution is intended to verify whether overheads (intended as general and structure expenses ratio over total revenues or expenses) can be an immediate, easy, and sufficient indicator for measuring the level of efficiency of public administration spending.

\section{Non-Profit Performance: A Review of the Literature}

\subsection{Non-Strategic Costs in the Non-Profit Sector}

If we consider business forms for the satisfaction of needs(Puddu et al., 2014), public companies are consumer companies that meet collective needs with the aim of income redistribution(Migliavacca, Rainero, \& Puddu, 2016). They differ from those of production in that they do not have direct access to the market, so the sources of financing are derived from taxes imposed by law, while the uses concern management costs, asset investments, and debt repayments (Migliavacca, Rainero, \& Puddu, 2016).

Keeping this interpretation key, another category belonging to consumer companies is that of nonprofit companies, which can be partially equated to public companies precisely because of the absence of a real reference market and the finding of sources of financing for carrying out the activity mainly from external contributions without consideration. The only difference is that such contributions cannot be imposed by law and are aimed at assisting and providing services and benefits to the community of reference, in the absence of profit and capital distribution (Bowman, Tuckman, \& Young, 2012; Hansmann, 1996).

If, therefore, in the public sector performance is mainly and historically linked to the management of financial resources and public debt (Pollitt, 2016), in the field of nonprofit there is different literature focused more on the control of economic aspects (and in particular the costs of the activity) as performance indicators of the company's activity.

The efficiency of nonprofit means, in general, the ability of the organization to achieve its mission at the lowest possible cost (Ecer, Magro, \& Sarpça, 2017). To assess the efficiency of these companies, one of the tools most used by donors, which represents the main source of funding (Duncan, 2004) is the incidence of so-called overheads. Overheads are non-strategic costs that, for the nonprofit sector, mainly consist of costs related to fundraising and salary costs (Portillo \& Stinn, 2018). This choice is mainly dictated by the ease of finding this information and the simplicity of reading it (Glassman \& Spahn, 2012).

At the international level, and in particular, in the United States, the use of overheads is an element of evaluation for the rating provided by Charity Navigator (which is based on data collected through the IRS Form 990, submitted by American nonprofits to benefit from tax exemption) whose website, according to the CEO, is consulted every year by more than three million donors who turn to this "controller" to find out where to hijack their donations (Glassman \& Spahn, 2012). It follows from these assessments that organizations with higher administrative expenses are the most penalized (Gneezy, Keenan, \& Gneezy, 2014) it is proven that the more overheads increase, the more donations decrease with an inversely proportional ratio (Woods Bowman, 2006). This is determined by the fact that donors want their donations to be used primarily for the nonprofit company and not to cover other costs, particularly those of fundraising (Portillo \& Stinn, 2018).

While it is true that donors prefer organizations where overhead and non-strategic costs are absent, where it is possible to find them, the choice to donate often falls preferentially on those organizations that have to cover fundraising expenses rather than those that use donations to cover wage costs(Gneezy, Keenan, \& Gneezy 2014).

More recently, other studies claim that the donors most committed to the cause are also those who accept higher levels of overhead (Newman et al., 2019). 
Surely the first problem to consider is how these overheads (non-strategic costs) are calculated. Already Cooper and Kaplan in the '80s and '90s of the other century had suggested the Activity-based costing method even if over the years it has been poorly used by companies due to its complexity and the need for people exclusively dedicated to data processing. An alternative solution with a more simplified method can be that of time-driven activity-based costing (Ringelstein, 2018).

The methodology for calculating overheads must, however, take into account the fact that these organizations are not all the same. They are very different in terms of age, size and sub-sector(Hager, Pollak, \& Rooney, 2001) and in terms of strength of structure (Hager, Pollak, \& Rooney, 2004) For example, it is proven that for social enterprises, which have a greater dependence on commercial revenues, is associated with greater efficiency in the management of general and administrative expenses, but at the same time with lower efficiency in fundraising(Ecer, Magro, \& Sarpça, 2017).

Considering that reducing overheads harms organizations' ability to launch fundraising campaigns, one solution is to find an initial donation to cover overheads. It is documented that this strategy increases donations by $80 \%$ (Gneezy, Keenan, \& Gneezy, 2014). This way, subsequent donations become "free" and go directly to the cause. If this start-up fund is not sufficient to cover all overheads, it should be used primarily to cover salary expenses. This sensitivity of donors and their aversion to overheads must be taken seriously by managers of nonprofit organizations (Portillo \& Stinn, 2018).

Other studies suggest that there is a correlation between the level of overheads and changes in equity and that a balance needs to be struck between reducing overheads and investment to achieve positive growth (Huang, 2014).

In the United States, according to The Donor Mindset Study, the average donor considers 19 percent acceptable overhead, even though the average for nonprofit organizations is 28 percent (Nonprofit Business Advisor 2018). Therefore, for the American average, 20 percent overhead can be considered reasonable as a benchmark to consider an efficient organization (Portillo \& Stinn, 2018).

The problem with this approach, as reported in the recent literature, is that it is not adequate to measure the level of efficiency of nonprofit organizations because it does not directly assess the degree to which these organizations can transform inputs into outputs (Coupet \& Berrett, 2019).

To calculate the business performance of the non-profit sector, especially at an international level, since a greater amount of classified data is available and accessible to all (see for example form 990 and Charity Navigator), the overhead evaluation tool can be considered outdated or to be exceeded, as suggested by the recent literature, as it is possible through this data to make more in-depth evaluations through more specific indicators, from the public sector point of view this indicator, in our opinion, can still be considered adequate.

\subsection{Overhead and Public Companies}

As indicated above, the types of nonprofit and public sector companies are generally included in the so-called "supply companies", whose purpose is not the production and exchange on the market of a good or service with the purpose of capital accumulation, but rather the provision of services worthy of protection, pursuing a higher moral "cause". For this reason, capital accumulation takes second place and so does cost efficiency. Thus, just as in the nonprofit sector the cause is to favor disadvantaged population groups or transmit moral values through its activity, in the public sector the main cause is to protect the population over which it has authority and power to govern through policies of income redistribution and protection of rights. It follows that, while on the nonprofit sector side, revenues are provided by voluntary donors, who prefer non-strategic cost levels and overheads, on the public sector side, revenues are forcibly withdrawn from the population, which loses the possibility of evading the withdrawal of money if the non-strategic costs are too high (thus constituting a source of inefficiency of public spending).

The first observation to make, therefore, is that what is defined as "non-strategic costs", or overheads for the nonprofit sector, in the public sector can be considered strategic. Non-strategic costs are costs linked to the purchase of factors not strictly related to business activity (non-productive factors). For the nonprofit sector, therefore, we consider as non-strategic costs the costs linked to "fundraising", limited to the costs for the acquisition of taxes and, subordinately, for tax controls, and personnel costs.

On the public administration side, on the other hand, the cost of personnel is a strategic cost as it is the productive factor through which public companies provide the services and its reduction must be linked to processes of efficiency gains in which the level of expenditure must depend on issues of needs and skills.

On the other hand, fundraising activity corresponds to the so-called "tax collection", i.e. the compulsory levy 
through taxation, the efficiency of which is generally assumed based on the impact of general and administrative costs on the tax revenue collected. The more this ratio tends to fall (reduction in administrative costs or increase in tax revenue through greater compliance, thus reducing tax evasion), the more the level of efficiency increases (OECD 2015, 162). Considering that the increase in the denominator (tax revenues) is not of immediate increase according to the policies of the public company, and constitutes a medium-long term tendential policy (fight against evasion, reforms of the tax system, etc...), it is, therefore, necessary to reduce overheads to improve the efficiency of public administration.

\section{Research Question and Methodology}

\subsection{Elements Underlying the Analysis}

Our analysis is based on a previous scientific contribution that carried out the analysis of overheads on almost all (Note 1) of the Italian municipalities (Rainero, 2019) and it emerged that, in the period 2013-2017, for medium and large municipalities ( $>5,000$ inhabitants), overheads reach a maximum of $20 \%$, while for smaller ones (up to 5,000 inhabitants) they reach $27-28 \%$.

We focused on the Italian public sector only, not to introduce in the analysis elements of disturbance due to the country differences in this preliminary analysis.

Our contribution questions the possibility of using overheads as a tool for an immediate and simple investigation of the efficiency of territorial public companies' spending.

In particular, this research raises the following question:

H. Is it possible to identify a level of overhead for which the likelihood of other positive performance indicators is maximized?

To carry out this analysis, the level of overhead specific to each municipality is compared with other performance indicators used at the national level to assess the performance and solidity of the municipalities; specifically, the deficit parameters set out in the Ministerial Decree of 28 December 2018 (Note 2) (hereafter called MINDEC), which follows and reproduces "the Guideline [...] on the revision of the parameters for the identification of structurally deficient local authorities [...]". (Note 3). This document identifies 8 parameters (defined as "deficits") used to assess the performance of municipalities and performance compared with other local authorities.

The analysis was conducted on all the Italian municipalities, equal to 7,983 existing in 2017 and surveyed by the AIDA-PA database of Bureau Van Dijk.

It is precisely by comparing the specific overhead levels for each institution with the performance indicators that it is possible to determine whether there is an "optimal" level of overhead where it is more likely that the municipality is in a situation of balance and good performance. Therefore, based on the indicators proposed in the Guideline, a comparative analysis has been carried out between these indicators and the impact of overheads on total verified revenue.

\subsection{Municipalities' Deficit Indicators}

The Guideline identifies 8 indicators to assess equal deficit levels for municipalities, metropolitan cities, and provinces. In the Guideline, for each indicator, there are thresholds above (or below) which the Entity can be considered "positive" and, consequently, performing and not in deficit. These thresholds are determined based on the percentiles of the distribution of the values assumed by the indicators, as recorded in the MINDEC. In particular, the thresholds have been set at the ninth decile (88-90th percentile) for parameters considered positive if the threshold is exceeded, or at the first decile (10-12th percentile) for parameters considered positive if the threshold is not exceeded. These indicators and the respective thresholds are shown in Table 1. 
Table 1. Deficit parameters and thresholds for municipalities

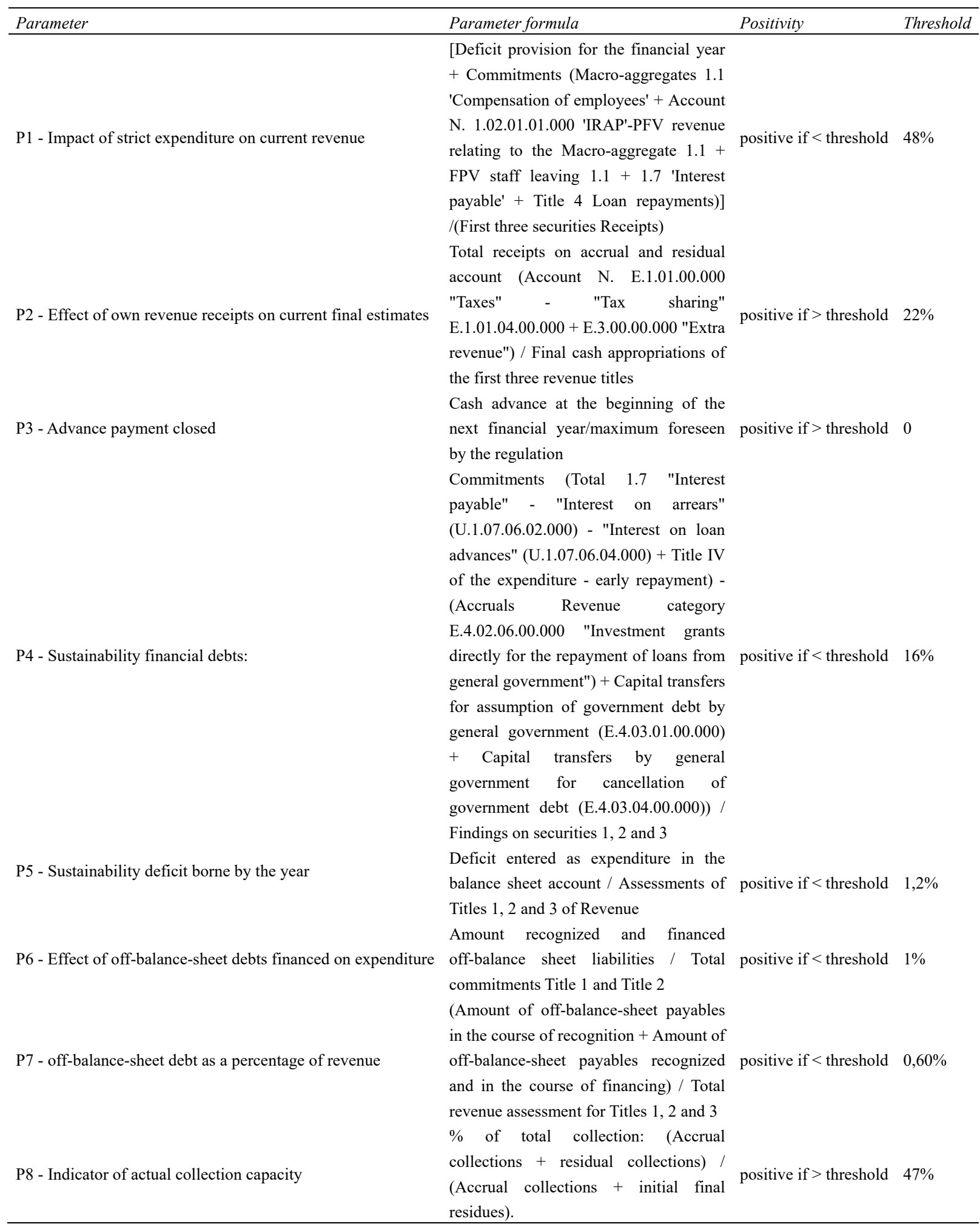

Source: Ministerial decree 28 December 2018.

For our analysis, it is necessary to recalculate these thresholds and also consider different distribution levels and percentiles. To consider thresholds corresponding to such extreme percentiles would lead to considering the vast majority of municipalities (about 90\%) as inefficient, non-performing, or deficient. The provision of such high thresholds by the Law is dictated by the purpose of benchmarking and improvement, while for our analysis it is 
necessary to establish different threshold levels (close to the median), to increase the sample of efficient municipalities.

\subsection{Data Collection}

For the calculation of the deficit parameters (hereinafter also referred to as 'indicators'), the variables in Table 2 have been extracted using the AIDA-PA database managed by Bureau Van Dijk.

Table 2. Variables extracted

\begin{tabular}{|c|c|c|}
\hline ID & Necessary variables & $\begin{array}{l}\begin{array}{l}\text { Situation of the } \\
\text { extraction }\end{array} \\
\end{array}$ \\
\hline 1 & Population & Extracted data \\
\hline 2 & Deficit indicators & Extracted data \\
\hline 3 & Title 1 Revenue - Established & Extracted data \\
\hline 4 & Title 2 Revenue - Established & Extracted data \\
\hline 5 & Title 3 Revenue - Established & Extracted data \\
\hline 6 & Total receipts E.1.01.00.000 - Competence and residue & Extracted data \\
\hline 7 & Total collections E.1.01.04.00.000 - Competence and residue & Extracted data \\
\hline 8 & E.3.00.00.000 - Non-recovered revenue & Extracted data \\
\hline 9 & Title 1 Revenue - Final cash appropriations & $\begin{array}{l}\text { Not present in the } \\
\text { database - variable } \# 3 \text { is } \\
\text { similar in size and } \\
\text { magnitude }\end{array}$ \\
\hline 10 & Title 2 Revenue - Final cash appropriations & $\begin{array}{l}\text { Not in the database - } \\
\text { variable } \# 4 \text { is of a } \\
\text { similar amount }\end{array}$ \\
\hline 11 & Title 3 Revenue - Final cash payments & $\begin{array}{l}\text { Not in the database - } \\
\text { variable } \# 5 \text { is of a } \\
\text { similar amount }\end{array}$ \\
\hline 12 & Revenue E.4.02.06.00.000 - Findings & Extracted data \\
\hline 13 & c/a for the assumption of debts from other AA.PP. E.4.03.01.00.000 - Transfers & Extracted data \\
\hline 14 & current accounts for debt cancellation E.4.03.04.00.000 - Transfers & Extracted data \\
\hline 15 & c/competence - Rewards & Extracted data \\
\hline 16 & w/residences - redeeming & Extracted data \\
\hline 17 & Overall findings & Extracted data \\
\hline 18 & Final initial residues & Extracted data \\
\hline 19 & Macro-aggregated commitments 1.1 - Employee income & Extracted data \\
\hline 20 & Commitments 1.02.01.01.000 - "IRAP & Extracted data \\
\hline 21 & FPV - Macroaggregate 1.1 & Not in the database \\
\hline 22 & FPV output personnel -Macroaggregate 1.1 & Not in the database \\
\hline 23 & 1.7 "Interest expense & Extracted data \\
\hline 24 & Title 4 - Loan Repayment & Extracted data \\
\hline 25 & Commitments 1.7 - Interest on arrears (U.1.07.06.02.000) & $\begin{array}{l}\text { Not present in the } \\
\text { database at this level of } \\
\text { detail }\end{array}$ \\
\hline 26 & Commitments 1.7 - Interest on loan advances (U.1.07.06.04.000) & $\begin{array}{l}\text { Not present in the } \\
\text { database at this level of } \\
\text { detail }\end{array}$ \\
\hline 27 & Title 4 Expenditure on early termination & Extracted data \\
\hline 28 & Title 1 - Commitments Expenditure & Extracted data \\
\hline 29 & Title 2 - Commitments Expenditure & Extracted data \\
\hline 30 & Deficit entered as expenditure in the balance sheet account & Not in the database \\
\hline 31 & Deficit recovery for the year & Not in the database \\
\hline 32 & Amount of off-balance-sheet payables recognized and financed & Extracted data \\
\hline 33 & Amount of off-balance-sheet payables in the process of being recognized & Not in the database \\
\hline 34 & Amount of off-balance-sheet payables recognized in the course of financing & Not in the database \\
\hline 35 & MISSION 1 Commitments & Extracted data \\
\hline 36 & Treasury advances at the beginning of the following year & Extracted data \\
\hline
\end{tabular}

Source: AIDA-PA by Bureau Van Dijk. 
The following indicators can be calculated from the data extracted (Table 3).

Table 3. Calculated indicators

\begin{tabular}{cc}
\hline Indicator & Formula (variable ID) * \\
\hline P1 & $\frac{31 * *+19+20-21 * *+22 * *+23+24}{3+4+5}$ \\
P2 & $\frac{6-7+8}{3+4+5}$ \\
P4 & $\frac{25^{* *}-26^{* *+24-(12+13+14)}}{3+4+5}$ \\
P8 & $\frac{15+16}{17+18}$ \\
\hline
\end{tabular}

Notes. *The numbers in this column refer to the "ID" column in Table 2 or 3.

** The figure is missing, therefore it is not taken into account in the calculation of the indicator.

It was not possible to reconstruct indicators P3, P5, P6, and P7 because insufficient data could be found to allow a relevant analysis based on them.

Source: formulas in the Addressing Document and reworked according to the variable numbers indicated in Table 2 or 3.

Concerning the data missing in the other indicators, however, having to recalculate the value of the indicator, the difference in values does not appear significant, also because these values are absent for all the Institutions considered. Therefore, these deficiencies are not to be considered relevant for the analysis in progress.

\subsection{The Calculation of Overheads and the "Clustering" of the Population of Municipalities}

Overheads were determined using the Mission and Programme Expense Classification approach(Rainero 2019). The basis of the analysis is the expenses contained in Mission 1 called Expenditure for "Institutional, General and Management Services" which considers the following strategic functions and objectives:

- Administration and operation of general services, statistical and information services, activities for the development of the entity from a governance and partnership perspective and institutional communication,

- Administration, operation, and support to executive and legislative bodies,

- Administration and operation of economic planning services in general and activities for business and financial and tax services,

- Development and management of personnel policies,

- Interventions within the framework of a single regional policy of a general nature and technical assistance.

Mission 1 is, in turn, made up of 11 programs:

- Program 01: Institutional bodies

- Program 02: General Secretariat

- Program 03: Economic management, financial management, programming, provisioning

- Program 04: Tax revenue management and tax services

- $\quad$ Program 05: Management of state property and assets

- Program 06: Technical Office

- Program 07: Popular elections and consultations - Civil registry and marital status

- Program 08: Statistics and information systems

- Program 09: Technical-administrative assistance to local authorities

- Program 10: Human Resources

- $\quad$ Program 11: Other general services(Rainero 2019)

For our analysis, we have considered as overheads the expenses contained in Programmes 01, 02, 03, 08, 10, and 
11. Therefore, Programmes 04, 05, 06, and 07 have been discarded as they refer to expenses incurred by municipalities to produce specific services (Rainero 2019).

To constitute an element of analysis, these expenses must be weighted and considered concerning the size of the institution. The benchmark used for the weighting is total verified revenue. Therefore, the percentage of overhead has been calculated as follows.

$$
\text { Overhead }(\%)=\frac{\text { Expenses obligations }}{\text { Established Revenues }}
$$

To perform the comparative analysis between overhead levels and indicator values, assuming continuous values, it is necessary to divide the variables into clusters based on the distribution of the values of the variables themselves.

The table below shows the clusters related to the percentage incidence of overheads calculated according to the previous formula.

In particular, clusters have been identified based on distribution percentiles, thus identifying $10 \%$ with the lowest values, $10 \%$ with the highest values, and four intermediate levels (which enclose $20 \%$ of municipalities each). The following table (Table 4) shows the overhead values assumed by the municipalities included in the clusters.

Table 4. Reference percentages for the calculation of thresholds (overhead incidence)

\begin{tabular}{lll}
\hline Cluster (overhead incidence) & Percentages of distribution considered & Overhead values included in the cluster \\
\hline Level 1 & From 0 to 10 percentile & $(0-7 \%]$ \\
Level 2 & $10^{\circ}$ to $30^{\circ}$ percentile & $(7-10 \%]$ \\
Level 3 & $30^{\circ}$ to $50^{\circ}$ percentile & $(10-13 \%]$ \\
Level 4 & $50^{\circ}$ to $70^{\circ}$ percentile & $(13-16 \%]$ \\
Level 5 & $70^{\circ}$ to $90^{\circ}$ percentile & $(16-24 \%]$ \\
Level 6 & From $90^{\circ}$ to $100^{\circ}$ percentile & (greater than 24\%) \\
\hline
\end{tabular}

The clusters for each indicator (deficit parameters) were also determined in the same way. The value of the limits (upper or lower) of each cluster is shown in the table below, indicating the reference percentile. The values are shown in Table 5a and $5 \mathrm{~b}$ refer to the values of the deficit parameters, determined as the results of the calculation of the parameter according to the methods explained in Table 3 in paragraph 3.2. above, taken from the quanta of the distribution indicated, in each reference year.

Table 5a. Reference percentages for the calculation of thresholds (indicators P1 and P4)

\begin{tabular}{|c|c|c|c|c|}
\hline Cluster & $\begin{array}{l}\text { Percentages } \\
\text { considered }\end{array}$ & Year & $\begin{array}{l}\text { P1 - Cluster upper limit } \\
\text { value }\end{array}$ & $\begin{array}{l}\text { P4 - Cluster upper limit } \\
\text { value }\end{array}$ \\
\hline \multirow{3}{*}{0 - Very bad } & \multirow{3}{*}{$\begin{array}{l}\text { From } 0 \text { to } 10 \\
\text { percentile }\end{array}$} & 2015 & $\max$ & $\max$ \\
\hline & & 2016 & $\max$ & $\max$ \\
\hline & & 2017 & $\max$ & $\max$ \\
\hline \multirow{3}{*}{1 - Insufficient } & \multirow{3}{*}{$10^{\circ}$ to $30^{\circ}$ percentile } & 2015 & $15,65 \%$ & $10,02 \%$ \\
\hline & & 2016 & $16,35 \%$ & $10,28 \%$ \\
\hline & & 2017 & $39,03 \%$ & $16,80 \%$ \\
\hline \multirow{3}{*}{2 - Sufficient } & \multirow{3}{*}{$30^{\circ}$ to $50^{\circ}$ percentile } & 2015 & $10,69 \%$ & $6,43 \%$ \\
\hline & & 2016 & $11,29 \%$ & $6,66 \%$ \\
\hline & & 2017 & $10,19 \%$ & $7,62 \%$ \\
\hline \multirow{3}{*}{3 - Good } & \multirow{3}{*}{$50^{\circ}$ to $70^{\circ}$ percentile } & 2015 & $7,57 \%$ & $4,37 \%$ \\
\hline & & 2016 & $8,22 \%$ & $4,65 \%$ \\
\hline & & 2017 & $6,05 \%$ & $3,96 \%$ \\
\hline \multirow{3}{*}{4 - Very good } & \multirow{3}{*}{$70^{\circ}$ to $90^{\circ}$ percentile } & 2015 & $4,67 \%$ & $2,63 \%$ \\
\hline & & 2016 & $5,40 \%$ & $2,98 \%$ \\
\hline & & 2017 & $3,92 \%$ & $2,45 \%$ \\
\hline \multirow{3}{*}{5 - Excellent } & \multirow{3}{*}{$\begin{array}{l}\text { From } 90^{\circ} \text { percentile } \\
\text { to } \max \end{array}$} & 2015 & $0,19 \%$ & $0,01 \%$ \\
\hline & & 2016 & $1,60 \%$ & $0,43 \%$ \\
\hline & & 2017 & $1,78 \%$ & $1,07 \%$ \\
\hline
\end{tabular}


Table 5b. Reference percentages for the calculation of thresholds (indicators P2 and P8)

\begin{tabular}{|c|c|c|c|c|}
\hline Cluster & $\begin{array}{l}\text { Percentages } \\
\text { considered }\end{array}$ & Year & $\begin{array}{l}\text { P2 - Cluster lower limit } \\
\text { value }\end{array}$ & $\begin{array}{l}\text { P8 - Cluster lower limit } \\
\text { value }\end{array}$ \\
\hline \multirow{3}{*}{0 - Very bad } & \multirow{3}{*}{$\begin{array}{l}\text { From max to } 90^{\circ} \\
\text { percentile }\end{array}$} & 2015 & 0 & 0 \\
\hline & & 2016 & 0 & 0 \\
\hline & & 2017 & 0 & 0 \\
\hline \multirow{3}{*}{1 - Insufficient } & \multirow{3}{*}{$\begin{array}{l}\text { From } 90^{\circ} \text { to } 70^{\circ} \\
\text { percentile }\end{array}$} & 2015 & $29,287 \%$ & $35,111 \%$ \\
\hline & & 2016 & $40,542 \%$ & $42,977 \%$ \\
\hline & & 2017 & $22,803 \%$ & $36,432 \%$ \\
\hline \multirow{3}{*}{2 - Sufficient } & \multirow{3}{*}{$70^{\circ}$ to $50^{\circ}$ percentile } & 2015 & $67,243 \%$ & $58,353 \%$ \\
\hline & & 2016 & $71,317 \%$ & $61,353 \%$ \\
\hline & & 2017 & $36,450 \%$ & $53,487 \%$ \\
\hline \multirow{3}{*}{3 - Good } & \multirow{3}{*}{$50^{\circ}$ to $30^{\circ}$ percentile } & 2015 & $80,380 \%$ & $67,838 \%$ \\
\hline & & 2016 & $85,024 \%$ & $70,372 \%$ \\
\hline & & 2017 & $42,301 \%$ & $63,667 \%$ \\
\hline \multirow{3}{*}{4 - Very good } & \multirow{3}{*}{$30^{\circ}$ to $10^{\circ}$ percentile } & 2015 & $87,603 \%$ & $74,679 \%$ \\
\hline & & 2016 & $92,006 \%$ & $77,372 \%$ \\
\hline & & 2017 & $45,836 \%$ & $72,276 \%$ \\
\hline \multirow{3}{*}{5 - Excellent } & \multirow{3}{*}{$\begin{array}{l}\text { From } 10 \text { to } 0 \\
\text { percentile }\end{array}$} & 2015 & $94,741 \%$ & $82,720 \%$ \\
\hline & & 2016 & $99,460 \%$ & $85,292 \%$ \\
\hline & & 2017 & $50,365 \%$ & $81,903 \%$ \\
\hline
\end{tabular}

The values of the thresholds determined are consistent with the parameters dictated by the ministerial decree of reference. In particular, the threshold value determined by the legislator has values substantially comparable to the values determined through recalculation and, in particular, equal to $39 \%$ for indicator P1 (MINDEC $=48 \%$ ), $22.80 \%$ for indicator P2 (MINDEC $=22 \%), 16.80 \%$ for indicator P4 (MINDEC $=16 \%$ ) and 36\% for indicator P8 $(\mathrm{MINDEC}=47 \%)$. The minor differences are due to the lack of existing data on some variables (in particular for indicator P1) or on some of the individuals in the sample observed (in particular for indicator P8).

\section{Data Analysis and Discussion}

\subsection{Correlation between Variables}

The first analysis that is carried out is purely descriptive and allows an overall analysis of the presence of a correlation between ministerial performance indicators and the level of the overhead of the municipalities.

As can be seen in Table 6, indicators P1 and P4 are negatively correlated with the level of overhead (calculated as the impact of overheads on revenue). This behavior, although the correlation is not particularly strong, shows a trend of direct correlation. This is consistent with the purpose of the indicators, which see an improvement of the indicator as it decreases. From this, it can be inferred that lower levels of overheads are expected when the performance of the institution improves, in line with what has already been specified in the existing literature.

Similarly, the P2 and P8 indicators are inversely correlated with the level of overhead. Similarly to the other indicators, the correlation is not particularly strong but shows an inversely proportional trend. This can be interpreted as worsening performance (as the indicators are better if they are high) as the level of revenue overhead increases.

For municipalities with a population of 5,000 inhabitants or less (small municipalities) this correlation is more evident, also due to the lower collection capacity, the size of the population living in the municipality, and the resulting lower spending capacity. The greatest correlation is expressed for indicators P8 (Indicator of collection capacity) and P1 (Indicator of incidence of rigid expenditure), followed by indicator P2 (Incidence of receipts on forecasts). By contrast, the indicator P4 (Sustainability of financial debts) shows a lower correlation.

For municipalities with a population of more than 5,000 inhabitants, on the other hand, the greatest correlation is given by indicators $\mathrm{P} 1$ and $\mathrm{P} 4$, while indicators $\mathrm{P} 2$ and $\mathrm{P} 8$ show a less significant correlation. 
Table 6. Analysis of the correlation between variables

\begin{tabular}{lllll}
\hline \multirow{2}{*}{ Indicator } & Correlation index () & & & \\
\cline { 2 - 5 } & Entire population & $\begin{array}{l}\text { Sample up to } 5,000 \\
\text { inhabitants }\end{array}$ & $\begin{array}{l}\text { Sample over } \\
\text { inhabitants }\end{array}$ & \\
\hline P1 & 0,1405 & 0,1584 & 0,1888 \\
P2 & $-0,0950$ & $-0,1227$ & $-0,0619$ & \\
P4 & 0,0954 & 0,0889 & 0,1790 & \\
P8 & $-0,1577$ & $-0,1771$ & $-0,0524$ & \\
\hline
\end{tabular}

Source: our processing.

From these correlation ratios, it can be argued that there is a correlation between the level of impact of overheads on revenues and the performance of the institution. It may also be argued that this correlation does not fully explain the performance of the institution, but is nevertheless a broad indicator that may, other things being equal, allow the economic performance of a public sector entity to be determined.

In the following paragraphs, we, therefore, try to determine an optimal overhead level by comparing the indicators with the incidence of overheads according to the (conditional) clusters defined above.

\subsection{Determination of the Optimal Overhead Level - Comparison of Overhead Levels with the Rigid Expense Incidence Indicator}

Indicator P1 determines the level of impact of 'hard expenditure' on total Revenue. This indicator has a trend inversely proportional to the performance of the institution and is considered better as the value of the indicator decreases. For this reason, as explained above, it shows a trend directly related to the impact of overheads on revenue, for which the greater the containment, the better the performance of the institution examined is considered. From Table 7 it is possible to analyze the absolute and relative distribution of entities within the crossed clusters. All tables show the distribution of municipalities without taking the reference year into account.

The research results explained in the table suggest that the lower the percentage of overheads, the better the indicator is likely to perform. In particular, for a level between zero and 7\% of expenditure most municipalities (with a ratio of 1 to 2) show indicators with a level at least equal to "Good" (above the median), with a preponderance of indicators equal to "Excellent" or "Excellent" (above the 70th percentile). The more the percentage incidence of overheads increases, the more this ratio is reduced until it is reversed for overheads above $10 \%$, with good results however up to $16 \%$.

The same analysis was also carried out by dividing the sample among municipalities with a population of less than 5,000 and more than 5,000 inhabitants. Let's consider the data referred to as the first sample: municipalities with a population of 5,000 inhabitants or less. This analysis shows how a low overhead value expresses values of the indicator closer to the "best" clusters, where the difference between the relative weights of the distribution remains high for overhead levels equal to or lower than $13 \%$, beyond which the difference between positive and negative indicators tends to assume a uniform distribution.

The analysis of the sample of municipalities with a population of over 5,000 inhabitants suggests even lower values, about $7 \%$. In fact, for overhead values above $7 \%$, the proportion between municipalities with performance indicators at least above the median and municipalities with indicator values below the median flattens out to tend to reverse.

From the analysis of the indicator, both at the population level and the level of samples based on the size of municipalities, it is, therefore, possible to define an optimal overhead threshold around $10 \%$, inversely proportional to the size of the municipality. In other words, from the analysis of the indicator, it is possible to define as most likely to perform municipalities with levels of general expenditure (overhead) that do not affect more than $10 \%$ of total revenue, with a margin of tolerance of $3 \%$ in positive for smaller municipalities and in negative for larger municipalities. 
Table 7. Overhead ratio clusters conditioned to P1 deficit parameter clusters for population distribution and population-based samples

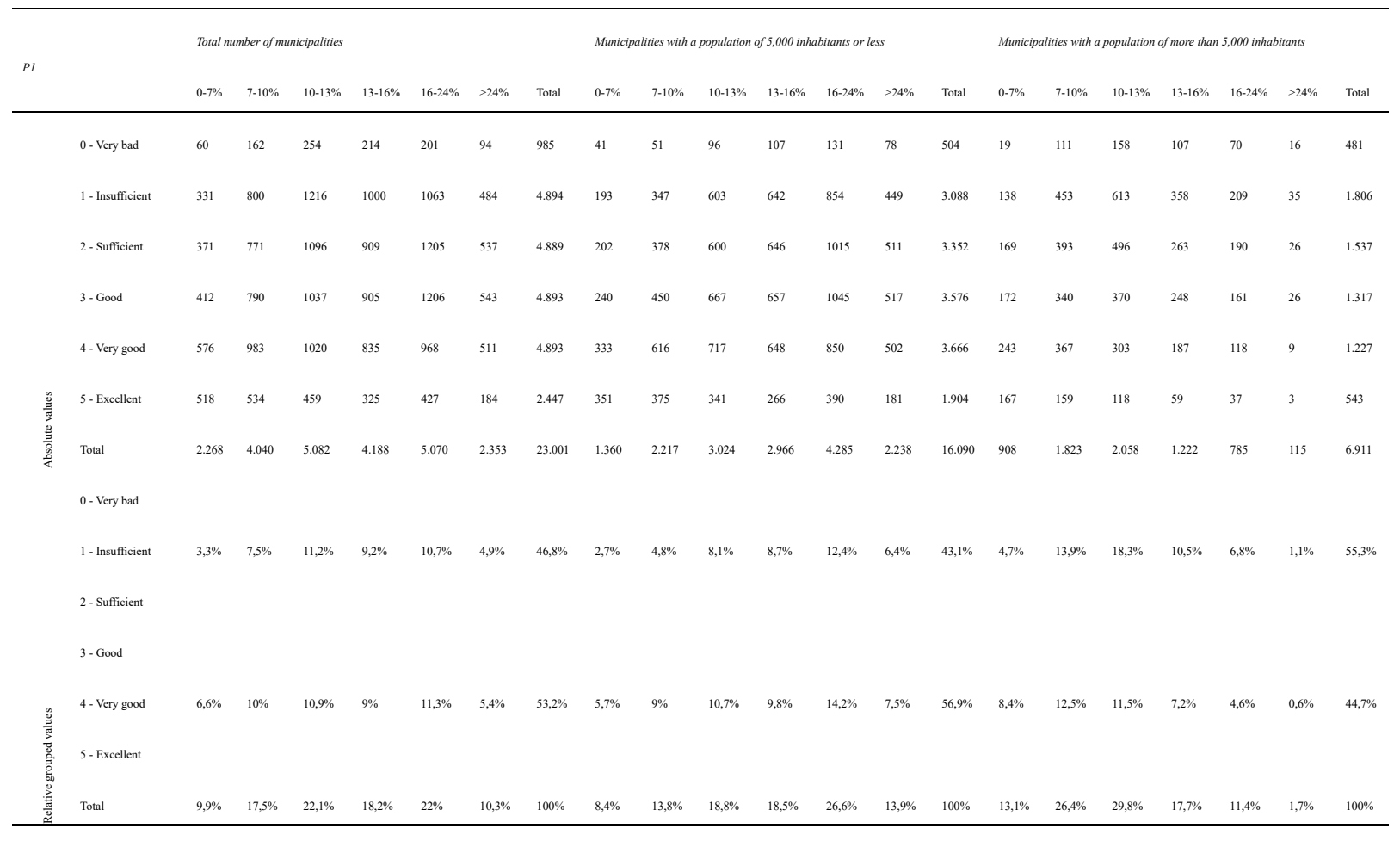

4.3 Determination of the Optimal Overhead Level - Comparison of Overhead Levels with the Indicator of the Impact of Own Revenue Receipts on Current Final Forecasts

Table 8 refers to the second indicator (P2) which, as already mentioned above, considers the impact of own revenue receipts on the current final forecast. When the indicator is higher, the municipality is considered to perform better. The correlation analysis shows that the indicator has an inversely proportional correlation with the level of overhead and, therefore, the lower and the incidence of this item, the better the performance levels should be.

From the analysis of the data at an overall level (Table 9), it can be seen that the distribution of the municipalities assumes values of the indicator mainly "good" with levels of overhead below $13 \%$, above which the majority of municipalities show results of the indicator below the median of the distribution. All tables show the distribution of municipalities without taking the reference year into account.

The best results, in any case, as for the previous indicator, are shown by municipalities with an incidence of overheads of $10 \%$ or less.

Also at sample level, the analysis shows similar results, with small municipalities showing a "good" trend in the indicator results for overhead levels up to $13 \%$ and larger municipalities showing a positive situation for levels below $10 \%$ and even better for levels below $7 \%$.

From the analysis of the indicator, both at the population level and the level of samples based on the size of the municipalities, it is, therefore, possible to define an optimal overhead threshold of around $13 \%$, with a margin of tolerance of $3 \%$ in positive for smaller municipalities and in negative for larger municipalities. 
Table 8. Clusters of overhead ratio conditioned to P2 deficit parameter clusters for population distribution and population-based samples

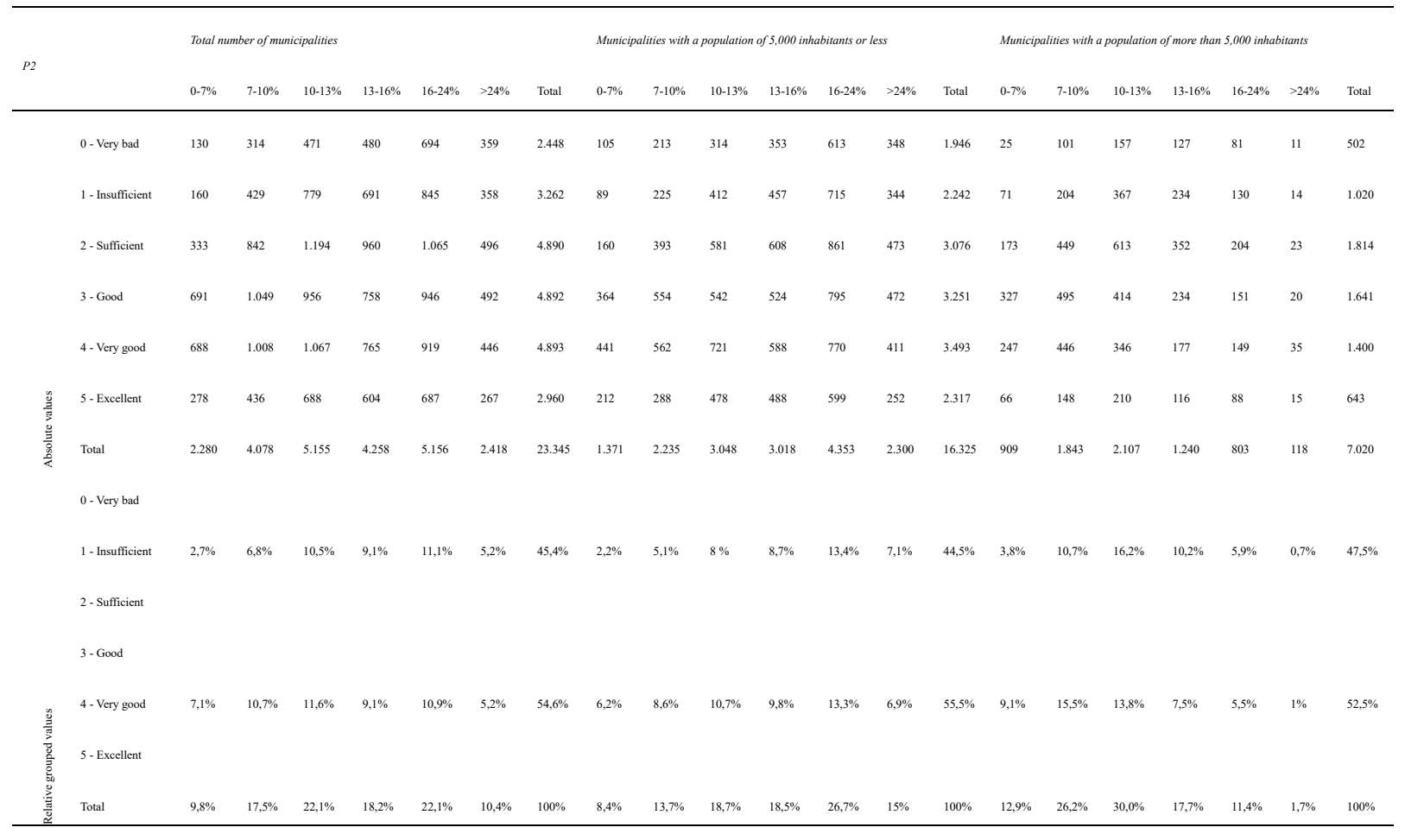

4.4 Determination of the Optimal Overhead Level - Comparison of Overhead Levels with the Financial Debt Sustainability Indicator

Table 10 refers to the third indicator (P4) which takes into account the sustainability of financial debts. The preliminary analysis showed that this indicator was more correlated with overheads in larger municipalities, while the correlation in small municipalities is of little relevance. This indicator shows a trend directly proportional to performance, so the higher it is, the less performing the municipality.

From the analysis of the data at an overall level (Table 9), it can be seen that the distribution of the municipalities assumes values of the indicator mainly "good" with all levels of overhead, with the best results, in any case, shown by municipalities with an incidence of the overhead of $10 \%$ or less. All tables show the distribution of municipalities without taking into account the reference year.

In small municipalities, as could already be inferred from the correlation analysis, there seems to be no particular influence on the incidence of overheads compared to the performance indicator linked to the sustainability of financial debts. In larger municipalities, on the other hand, for overhead levels below 7\%, there is a large preponderance of municipalities with "good" indicator levels (in particular, "excellent" level), while for higher levels there is an increasing preponderance of indicators below the median.

From the analysis of the indicator, both at the population level and the level of samples based on the size of municipalities, it is, therefore, possible to define an optimal overhead threshold of around 10\%, particularly for large municipalities, for which the incidence must be less than $7 \%$.

\subsection{Determination of the Optimal Overhead Level - Comparison of Overhead Levels with the Actual Collection Capacity Indicator}

Considering the fourth indicator (P8), which refers to the actual collection capacity, it shows an inverse correlation with the level of overhead and, therefore, the higher the incidence of this item, the better the performance levels should assume.

From the analysis of the distribution of municipalities in the various clusters (Table 10), the data suggest that overhead levels should not exceed $10 \%$ because above this level municipalities tend to be in the worst clusters of the indicator. All tables show the distribution of municipalities without taking the reference year into account.

In particular, from the analysis of samples of small and large municipalities, the analysis on the P8 indicator 
shows that the threshold value is $10 \%$ without particular differences and tolerance thresholds.

Table 9. Overhead ratio clusters conditioned to P4 deficit parameter clusters for population distribution and population-based samples

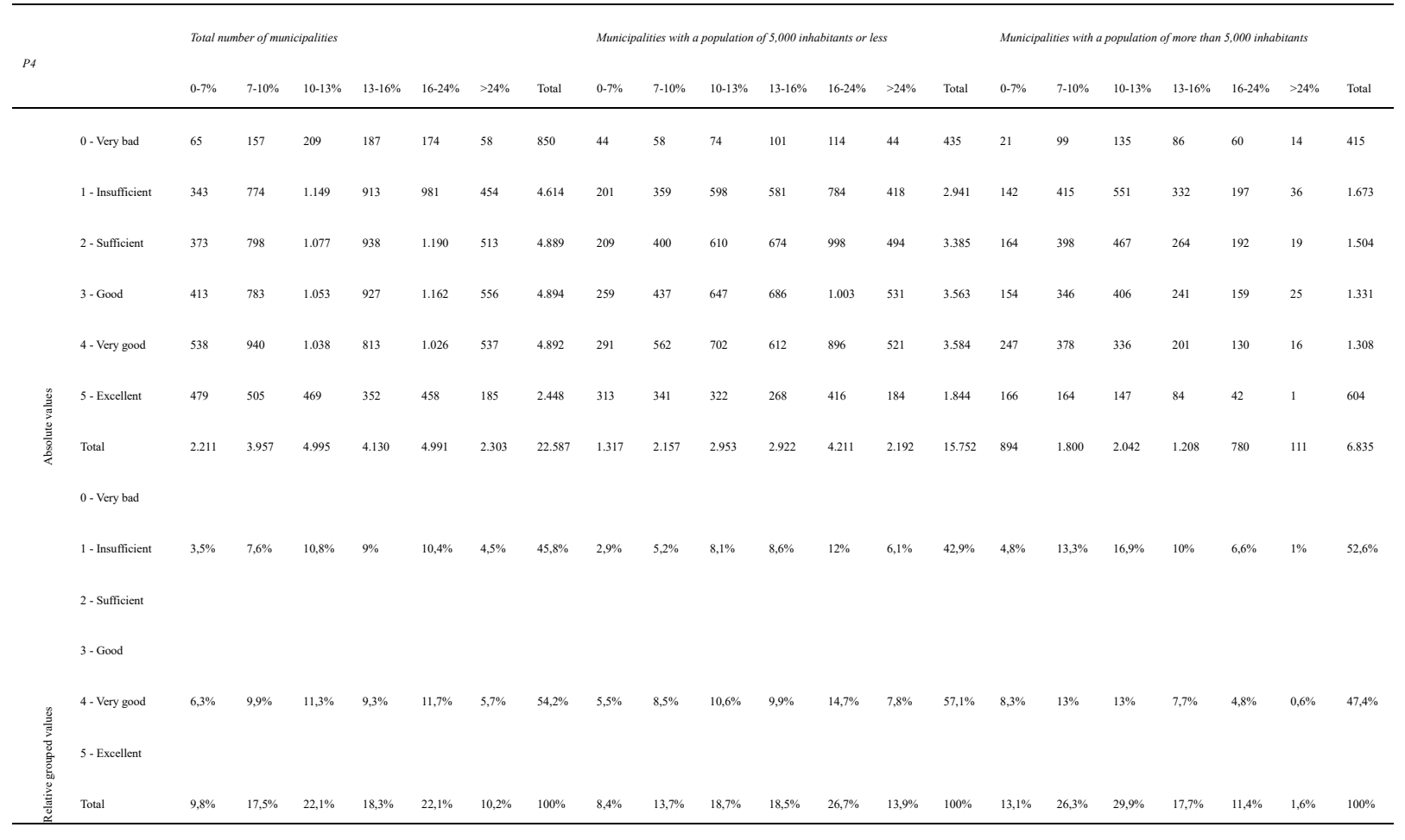

Table 10. Clusters of overhead ratio conditioned to P8 deficit parameter clusters for population distribution and population-based samples

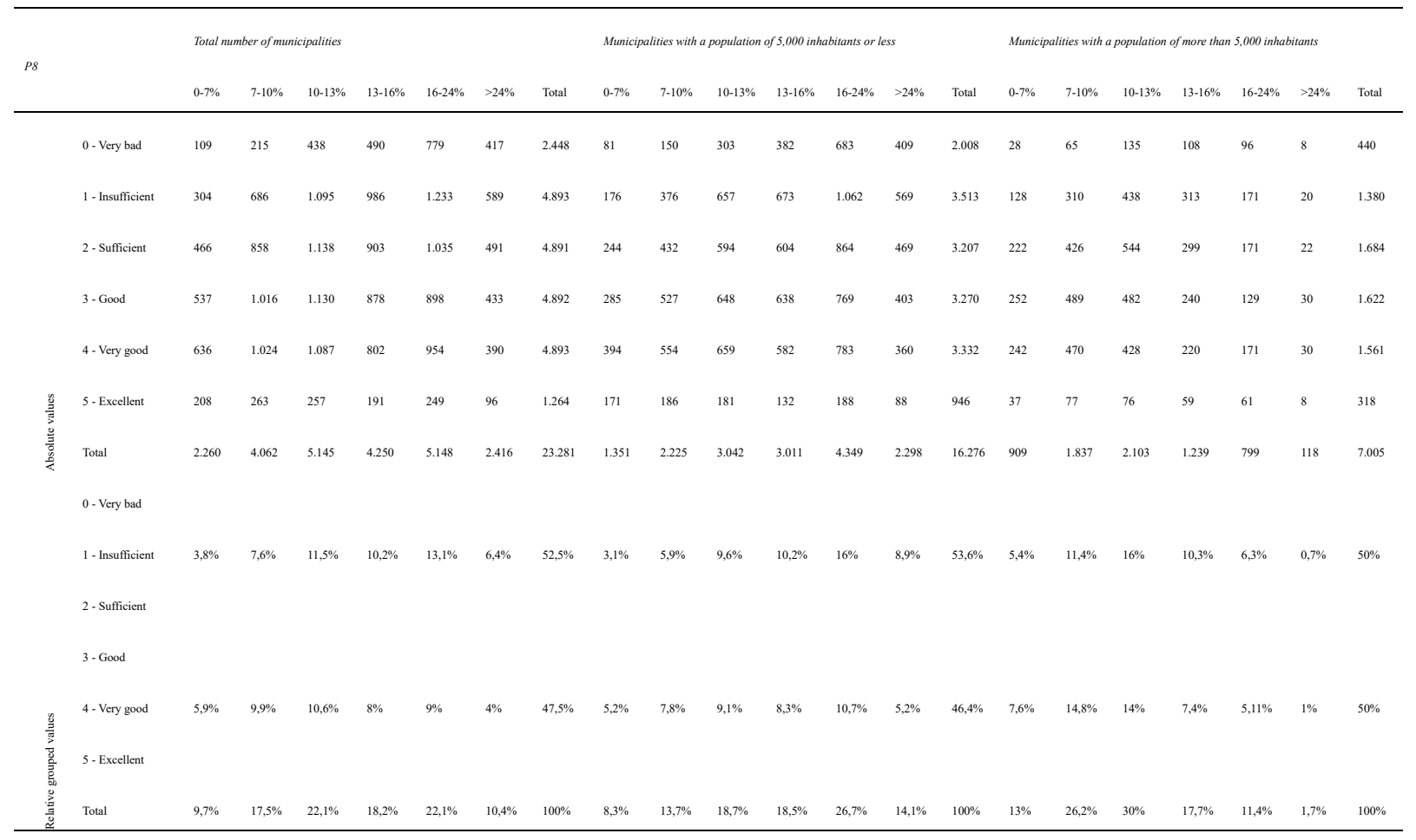




\section{Conclusions and Future Developments}

The analysis carried out shows that the level of overhead shows a correlation, although not particularly significant, with other performance indicators used to assess the performance of municipalities. In particular, this correlation is because the other indicators primarily consider data of a financial nature, originating from the financial accounts of the entities, while the overheads themselves should be calculated starting from the results of the economic-equity accounts, which is closely linked to the financial accounts employing the transposition matrix of the Plan of Accounts but which includes further considerations in terms of accrual and evaluation of the result for the year.

From the study of the distribution of the municipalities in the various clusters (levels) of the indicator conditioned to the clusters (levels) of the incidence of overheads on the income of the entity, both at the population level and at the level of samples based on the size of the municipalities, it is, therefore, possible to define an optimal overhead threshold around $10 \%$, inversely proportional to the size of the municipality.

In particular, as demonstrated in the previous paragraph, an analysis of the indicators shows that municipalities are most likely to perform well in cases where levels of general expenditure (overhead) do not account for more than $10 \%$ of total revenue, with a margin of tolerance of $3 \%$ in positive for smaller municipalities and $3 \%$ in negative for larger municipalities.

This research is limited by the fact that it is a preliminary, albeit in-depth, analysis, mainly aimed at verifying the existence of a correlation between certain levels of overhead and other indicators of efficiency of public enterprises. Moreover, it has not been possible to calculate some indicators due to lack of data and the analysis could be flawed in this sense, although it maintains intrinsic robustness due to the application of the same calculation to the whole universe of Italian municipalities.

Future research developments will focus on investigating the underlying reasons for the correlations identified, to determine whether there is a causal relationship in reducing overall spending levels and improving the institution's performance with a time development approach and analysis of a historical series, as well as determining other disruptive factors and their weight in assessing the institution's performance.

\section{References}

Anessi Pessina, E. (2018). L'armonizzazione contabile nel settore pubblico italiano. Implicazioni per le regioni e per i servizi sanitari regionali. Retrieved from http://ojs.francoangeli.it/_omp/index.php/oa/catalog/book/388

Bowman, W. (2006). Should Donors Care About Overhead Costs? Do They Care? Nonprofit and Voluntary Sector Quarterly, 35(2), 288-310. https://doi.org/10.1177/0899764006287219

Bowman, W., Tuckman, H. P., \& Young, D. R. (2012). Issues in Nonprofit Finance Research: Surplus, Endowment, and Endowment Portfolios». Nonprofit and Voluntary Sector Quarterly, 41(4), 560-579. https://doi.org/10.1177/0899764011411925

Brusca, I., Eugenio, C., Sandra, C., \& Francesca, M. R. (2016). Public Sector Accounting and Auditing in Europe: The Challenge of Harmonization.

Coupet, J., \& Jessica, L. B. (2019). Toward a Valid Approach to Nonprofit Efficiency Measurement. Nonprofit Management and Leadership, 29(3), 299-320. https://doi.org/10.1002/nml.21336

Duncan, B. (2004). A theory of impact philanthropy. Journal of Public Economics, 88(9), 2159-2180. https://doi.org/10.1016/S0047-2727(03)00037-9

Ecer, S., Mark, M., \& Sinan, S. (2017). The Relationship Between Nonprofits' Revenue Composition and Their Economic-Financial Efficiency. Nonprofit and Voluntary Sector Quarterly, 46(1), 141-155. https://doi.org/10.1177/0899764016649693

Glassman, D. M., \& Kathy, S. (2012). Performance Measurement for Nonprofits. Journal of Applied Corporate Finance, 24(2), 72-77. https://doi.org/10.1111/j.1745-6622.2012.00381.x

Gneezy, U., Elizabeth, A. K., \& Ayelet, G. (2014). Avoiding Overhead Aversion in Charity. Science, 346(6209), 632-635. https://doi.org/10.1126/science.1253932

Hager, M. A., Thomas, P., \& Patrick, R. (2001). Variations in overhead and fundraising efficiency measures: The influence of size, age, and subsector.

Hager, M. A., Thomas, P., \& Patrick, R. (2004). Getting what we pay for: Low overhead limits nonprofit effectiveness. Nonprofit Overhead Cost Project, Brief No. 3 from the Center on Nonprofits and 
Philanthropy at the Urban Institute and the Center of Philanthropy at Indiana University.

Hansmann, H. (1996). The changing roles of public, private, and nonprofit enterprise in education, health care, and other human services. In Individual and social responsibility: Child care, education, medical care, and long-term care in America (pp. 245-276). University of Chicago Press.

Huang, S. S. (2014). Does Overhead Spending Affect Fiscal Performance of Nonprofits?

Migliavacca, A., Christian, R., \& Luigi, P. (2016). Aziende, amministrazione razionale e impatto sociale.

Miller, P., \& Michael, P. (2013). Accounting, Organizing, and Economizing: Connecting Accounting Research and Organization Theory. https://doi.org/10.1080/19416520.2013.783668

Newman, G. E., Adam, S., Daylian, M. C., \& Kyle, S. (2019). Do the Ends Justify the Means? The Relative Focus on Overhead Versus Outcomes in Charitable Fundraising. Nonprofit and Voluntary Sector Quarterly, 48(1), 71-90. https://doi.org/10.1177/0899764018794903

Nonprofit Business Advisor. (2018). Donors not as concerned about nonprofit overhead ratios as believed, study shows. $\quad$ Retrieved from http://web.a.ebscohost.com/ehost/pdfviewer/pdfviewer?vid=9\&sid=e7bce5c2-38d0-4197-ac6e-db100b99f9 $09 \% 40$ sessionmgr4006

OECD. (2015). Government at a Glance 2015. OECD Publishing; Éditions OCDE.

Pollitt, C. (2016). Advanced Introduction to Public Management and Administration. Edward Elgar Publishing.

Portillo, J. E., \& Joseph, S. (2018). Overhead aversion: Do some types of overhead matter more than others? Journal of Behavioral and Experimental Economics, 72, 40-50. https://doi.org/10.1016/j.socec.2017.11.003

Puddu, L., Alessandra, I., Massimo, P., Christian, R., Silvana, S., Enrico, S., \& Vania, T. (2014). Appunti di "Ragioneria pubblica applicata".

Rainero, C. (2019). L'incidenza delle spese generali (o «overhead») nelle amministrazioni pubbliche. RIREA.

Ringelstein, D. (2018). Time-Driven Activity-Based Cost Accounting: A Critical Review. Journal of New Business Ideas \& Trends, 16(3), 20-27.

\section{Notes}

Note 1 . About $90 \%$, as $10 \%$ was discarded due to lack or incompleteness of data.

Note 2. Decree of the Minister of the Interior in agreement with the Minister of Economy and Finance for the identification of structural deficit parameters for local authorities for the three-year period 2019-2021 (art. 242 of Local Public Sector Law, Legislative Decree 267/2000 (TUEL)).

Note 3. Guidance document according to Article 154, paragraph 2, of the Consolidated Law on Local Authorities, approved by Legislative Decree No. 267 of 18 August 2000.

\section{Copyrights}

Copyright for this article is retained by the author(s), with first publication rights granted to the journal.

This is an open-access article distributed under the terms and conditions of the Creative Commons Attribution license (http://creativecommons.org/licenses/by/4.0/). 